\title{
É a educação ética uma forma de violência contra o educando?
}

Bruno Pucci

Universidade Metodista de Piracicaba

\section{Resumo}

Chauí, no livro Convite à Filosofia, lança uma questão instigante para os educadores: não seria a educação ética uma forma de violência contra o ser humano? Primeiramente, porque visa transformar-nos de seres passivos em ativos; se nossa natureza é passional, impulsionada por nossos instintos, forçarnos à racionalidade ativa não seria violência contra a natureza espontânea? Se a educação ética se propõe a colocar-nos em conexão com os valores da sociedade, não seria isso submissão ao poder externo e, nesse caso, em vez de sujeitos autônomos, não seríamos escravos das normas e valores impostos pela sociedade? Este texto se propõe, a partir das contribuições de Kant, Durkheim e Adorno, analisar os questionamentos de Chauí e trazer contribuições para a formação ética de nossos educandos e educadores.

Palavras-chave: Educação ética. Educação em Kant. Educação para Durkheim. Educação para Adorno. Tensão entre indivíduo e sociedade. 


\section{Is Ethics Education a form of violence against the student?}

Chauí, in her book Convite à Filosofia (2006, p. 310) asks a compelling ethical question to educators: would ethics education be a form of violence against human beings? First, because it seeks to transform us from passive beings into active beings; if our nature is passionate, driven by our instincts, wouldn't forcing rationality upon us be an act of violence against spontaneous nature? If ethics education aims to connect us with the values of society, wouldn't it be a submission to an external power, and in this case, instead of autonomous individuals, wouldn't we be the slaves of norms and values imposed by society? Based on the contributions of Kant, Durkheim and Adorno, this paper aims at analyzing the questions asked by Chauí, and making contributions to the ethics education of our students and educators.

Keywords: Ethics Education. Education in Kant. Education in Durkheim. Education in Adorno. Tension between the individual and society.

\section{¿Es la educación ética una forma de violencia contra el educando?}

Marilena Chauí, en su libro Convite à Filosofia (2006, p. 310), lanza una cuestión ética inquietante para los educadores que merece ser analizada. La filósofa pregunta si la educación ética no sería una forma de violencia contra el ser humano. Primeramente, porque si se propone transformarnos de seres pasivos en activos si nuestra naturaleza es esencialmente pasional, impulsada por nuestros instintos, ¿forzarnos a la racionalidad activa no sería un acto de violencia contra la naturaleza espontánea, ya que violencia es forzar a alguien a sentir y actuar de manera contraria a su naturaleza? Después de todo, si la educación ética se propone colocarnos en conexión con los valores de la sociedad, en que nacemos y somos criados, ¿no sería eso una sumisión a un poder externo a nuestra conciencia, el poder moral y social? Y, en ese caso, en vez de sujetos autónomos, libres, ¿no seríamos esclavos de las normas, reglas y valores impuestos por la sociedad? Este texto se propone, a partir de las contribuciones de Kant, Durkheim y Adorno, analizar el cuestionamiento de Chauí en sus dos momentos específicos y complementarios y, con eso, aportar contribuciones para la formación ética de nuestros educandos y educadores.

Palabras clave: Educación ética. La educación en Kant. La educación para Durkheim. La educación para Adorno. Tensión entre individuo y sociedad. 


\section{Introdução}

(...) a deformação não é nenhuma doença no homem e sim uma doença da sociedade, que gera suas crias com aquela "tara hereditária" que o biologismo projeta na natureza. (Adorno, 1992, p. 201; 2008, p. 226).

Marilena Chauí, em seu livro Convite à Filosofia (2006, p. 310), lança uma questão ética instigante para os educadores, que merece ser analisada. Pergunta a filósofa se não seria a educação ética uma forma de violência contra o ser humano. Primeiramente, porque visa transformar-nos de seres passivos em ativos; se nossa natureza é essencialmente passional, impulsionada por nossos instintos, forçar-nos à racionalidade ativa não seria um ato de violência contra a natureza espontânea, já que violência é forçar alguém a sentir e agir de maneira contrária à sua natureza? Além do mais, se a educação ética se propõe a colocar-nos em conexão com os valores da sociedade em que nascemos e somos criados, não seria isso uma submissão a um poder externo à nossa consciência, o poder moral e social? E, nesse caso, em vez de sujeitos autônomos, livres, não seríamos escravos das normas, regras e valores impostos pela sociedade? Este texto se propõe a analisar o questionamento de Chauí em seus dois momentos específicos e complementares e, com isso, trazer contribuições para a formação ética de nossos futuros docentes. E o fará a partir de Kant, Durkheim e, sobretudo, de Adorno. Na primeira parte do trabalho, serão apresentadas considerações do filósofo de Königsberg; a seguir, o que pensa Durkheim e, com mais detalhe, na parte final, por meio de aforismos extraídos das Minima Moralia, a argumentação de Adorno sobre a questão.

O que está em jogo no questionamento de Chauí não é apenas a conceituação de educação ética, a tensão histórica entre necessidade e liberdade humana, entre indivíduo e sociedade, mas, sobretudo, a sobrevivência do indivíduo em tempos do poder quase totalitário do social. E o primeiro pensador a quem solicitamos a resposta para a questão é Immanuel Kant, que viveu na antiga Prússia, de 1724 a 1804, e desenvolveu reflexões substanciais sobre ética, educação e autonomia do indivíduo. "O homem é uma criatura que precisa ser educada”, diz o filósofo, “o homem não pode tornar-se um verdadeiro homem senão pela educação. Ele é aquilo que a educação faz dele". E o que significa a educação? "Por educação entende-se o cuidado de sua infância (a conservação, o trato), a disciplina e a instrução com a formação" (Kant, 1996, p. 11 e 13). É pela disciplina que a animalidade se transforma em humanidade. Não existe bondade natural naquela criaturinha que nasce, como pensava Rousseau; ela é, por natureza, egoísta, destrutiva, agressiva, ávida de prazeres, como todo "bom selvagem"; e é a disciplina que vai domar sua selvageria; é ela que impede o homem de desviar-se de sua humanidade. Disciplinar é procurar 
impedir que a animalidade prejudique o caráter humano, tanto no indivíduo quanto na sociedade. (Kant, 1996, p. 12 e 23).

Ainda no Sobre a Pedagogia', Kant pergunta se o homem é moralmente bom ou mau por natureza e responde que ele se torna moral apenas quando se utiliza de sua razão por dever e pela lei; o homem apresenta tendências originárias para todos os vícios, e as inclinações e instintos podem levá-lo para a destruição se sua razão e vontade não intervierem (1996, p. 102). Ou seja, é a educação por meio da disciplina, é a razão prática através do dever, da lei moral, que faz com que a humanidade do homem seja preservada e desenvolvida.

Assim, para Kant, a educação ética é mesmo uma forma de violência contra a natureza espontânea do ser humano, para domar, pela ação da disciplina, os desejos e as paixões que são constitutivos da espécie. Ao mesmo tempo, se o ser humano se caracteriza por sua racionalidade e liberdade, por que os valores e normas morais não the são igualmente espontâneos à sua vontade e precisam assumir a forma do dever, de uma lei?

0 pensador de Königsberg (sua cidade natal), nas "Lições de Pedagogia”, já tinha analisado essa tensão existencial e imanente no homem entre sua natureza e racionalidade; a primeira é o reino da necessidade, da causalidade, em que o corpo e a psique humana (sentimentos, emoções, comportamentos) estão submetidos aos apetites, impulsos e instintos provindos de sua própria constituição. Mas, como o homem não é apenas natureza, ele deve dominá-los para expressar sua liberdade e desenvolver o mais plenamente possível a humanidade. É submetendo a animalidade que o homem atinge a humanidade. Em outros termos, a submissão dos desejos à vontade e à razão não deixa de ser um ato de violência, mas uma violência necessária para se realizar um fim superior, o de ser livre, o de ser homem. Entretanto, Kant admite outra forma de constrangimento na educação ética: o de conciliar a obediência à lei moral com o exercício de liberdade. 0 constrangimento é necessário, mas é preciso habituar o educando a suportar que a sua liberdade seja submetida ao constrangimento de outrem e que, ao mesmo tempo, dirija-a corretamente; é necessário que ele sinta logo a inevitável resistência da sociedade, que ele tolere as privações e adquira o que é necessário para tornar-se independente; é preciso provar que o constrangimento, que lhe é imposto, tem por finalidade ensinar-lhe a usar bem da sua liberdade (Kant, 1996, p. 34-35). Ou seja, Kant em nenhum momento abre mão da busca da autonomia pelo indivíduo.

Em seu livro mais importante sobre a moral, Crítica da Razão Prática, faz-nos ver que a liberdade prática é a independência da vontade em relação a toda outra lei que não seja a lei moral. Ser livre é ser capaz de obedecer à razão, fundamento do dever.

1. O livro de Kant, Sobre a Pedagogia, é resultante de suas aulas ministradas nos anos 1776/77, 1783/84 e 1786/87 (Cf. Prefácio à Edição Brasileira, In Kant, 1996). 
Se a liberdade prática consiste na obediência à lei moral, mister se faz que o homem não se encontre submetido à determinação da natureza. Ser livre é não depender da compulsão das inclinações, mas o homem não se libertará dessa compulsão, se não for livre absolutamente. Na medida em que existe no tempo, ele está sujeito à lei mecânica do encadeamento dos fenômenos; toda ação que ocorre num dado instante é condicionada por aquilo que ocorreu antes. Logo, enquanto se encontra inserida no mundo dos fenômenos, a ação humana não é livre. A solução esboçada na Crítica consiste na distinção do homem enquanto fenômeno, sujeito à necessidade natural, do homem considerado como "noumenon" ou livre. Em outros termos, no mundo sensível, as ações do homem estão ligadas por um encadeamento rigoroso. Mas no mundo inteligível, que foge ao tempo, nada é anterior à determinação de sua vontade (Pascal, 1990, p. 137). Então, o homem precisa obedecer à lei moral, e essa obediência é facilitada pelo sentimento de respeito; e só há respeito onde há um esforço em busca do bem, do dever. São de uma sensibilidade intensa e de uma profundeza admirável as palavras que Kant reserva para conceituar o poder, a força e a sublimidade da expressão dever, que sintetiza em seu regaço a tensão entre a submissão e a liberdade do homem que age moralmente:

Dever! Nome sublime e grande, tu que nada conténs de amável ou lisonjeiramente sedutor, mas exiges submissão, e, todavia, para mover a vontade não despertas na alma, com ameaças, nenhuma aversão natural ou temor, mas propões simplesmente uma lei que por si mesma encontra acolhida na alma e, não obstante, e mesmo à nossa revelia conquista a veneração (embora nem sempre a observância), uma lei que faz emudecer todas as inclinações, ainda que secretamente a contrariem; que origem haverá que seja digna de ti? E onde se encontra a raiz de tua nobre estirpe, que recusa com altivez todo parentesco com as inclinações, raiz donde é mister proceda, como de sua origem, a condição indispensável daquele único valor que os homens podem dar-se a si mesmos? (Kant, 1994, p. 102).

E o que Emile Durkheim responderia ao questionamento posto por Marilena Chauí? Durkheim, considerado um dos fundadores da sociologia moderna, viveu na França nos anos de 1858 a 1917. Em seu texto "Educação e sociologia" (1995) critica as ideias de Kant sobre a educação, pois partiriam de uma concepção ideal, perfeita, apropriada a todos os homens indistintamente, esquecendo-se de considerar a história, que mostra que a educação tem variado infinitamente com o tempo e o espaço. Em seu conceito de educação ética, Durkheim enfatiza o poder, a força do social sobre o indivíduo. Diz ele:

A educação é a ação exercida pelas gerações adultas sobre as gerações que não se encontram ainda preparadas para a vida social; tem por objeto suscitar e desenvolver, na criança, certo número de estados físicos, intelectuais e morais, reclamados pela 
sociedade política no seu conjunto e pelo meio especial a que a criança, particularmente, se destine. (Durkheim, 1995, p. 25).

Uma sociedade ou um grupo social, para se desenvolver, precisa impor aos indivíduos, e de um modo irresistível, um sistema de educação, ao qual se devem conformar. “É uma ilusão - diz ele - pensar que podemos educar nossos filhos como queremos" (1995, p. 26). Durkheim admite a dimensão subjetiva da educação; para ele, em cada homem existem como que dois seres: um que se relaciona com os acontecimentos da vida pessoal e se poderia chamar "ser individual"; e o outro, que é um sistema de ideias, sentimentos e hábitos, que exprimem no indivíduo não a sua personalidade, mas os grupos diferentes de que faz parte; seu conjunto forma o "ser social”. Mas o objetivo da educação é constituir esse ser social em cada indivíduo. Para ele, também, o ser individual que nasce é egoísta, associal; é preciso que a sociedade, pelos meios mais rápidos, agregue a ele uma segunda natureza, moral e social; e a sociedade realiza essa obra por meio da educação ética; ela cria no homem um ser novo. Se se retirasse do homem tudo quanto a sociedade the forneceu, ele retornaria à condição de animal. Se ele pôde ultrapassar o estádio em que os animais permanecem é porque não se conformou apenas com o resultado de seus esforços pessoais, mas cooperou com seus semelhantes na construção de algo melhor, e isso veio reforçar o rendimento da atividade de cada um.

Quando as organizações sociais eram mais simples, com poucas variações, era suficiente a tradição, como para o animal é suficiente o instinto; nessa situação, os que desenvolviam um pouco mais o saber, o livre pensar, eram tidos como perigosos e, por isso, eram proscritos. Quando a vida social, sob todas as formas, tornou-se mais complexa e se exigiu que se desenvolvesse o pensamento refletido, então a cultura científica se tornou necessária: “é essa a razão pela qual a sociedade a reclama de seus membros e a impõe a todos, como um dever" (Durkheim, 1995, p. 28). Se em Kant o dever se fundamenta numa exigência interna e objetiva da razão, por ser aquela faculdade, ao mesmo tempo, particular e universal, constitutiva da humanidade do indivíduo, em Durkheim o dever se torna universal, naquele grupo social, por exigência destemesmo, de sua continuidade.

Para Durkheim, pois, a moral acha-se estreitamente relacionada com a natureza das sociedades; ela muda quando as sociedades mudam; ela resulta da vida em comum. É a sociedade que obriga as pessoas a considerarem outros interesses que não os individuais, que thes ensina a dominar as paixões, os instintos, que lhes dá uma lei, que lhes impõe o sacrifício, a privação, a subordinação dos fins individuais a outros mais elevados. Todo o sistema de representação, que mantém nas pessoas a ideia e o sentimento da lei, da disciplina interna ou externa, é instituído pela sociedade (1995, p. 29). 
Dessa forma,Então, se os indivíduos só agem em conformidade com as exigências sociais, como a análise do texto de Durkheim nos faz supor, a sociedade não thes estaria impondo uma tirania insuportável, exigindo deles uma submissão incondicional, debilitando-lhes a liberdade? 0 pensador francês responde que esse suposto antagonismo muitas vezes admitido entre indivíduos e sociedade não corresponde à coisa alguma no terreno dos fatos; longe de estarem em oposição ou de se desenvolverem em sentido diverso, indivíduo e sociedade dependem um do outro; e o indivíduo, ao desejar melhorar a sociedade, melhora a si mesmo. Para ele,

(...) a ação exercida pela sociedade, especialmente através da educação, não tem por objeto, ou por efeito, comprimir o indivíduo, amesquinhá-lo, desnaturá-lo, mas ao contrário engrandecê-lo e torná-lo criatura verdadeira humana. Sem dúvida, o indivíduo não pode engrandecer senão pelo próprio esforço. 0 poder do esforço constitui, precisamente, uma das características essenciais do homem. (Durkheim, 1995, p. 30).

E, Durkheim concluiria sua resposta à questão de Chauí, destacando que os homens mesmos estão interessados nessa submissão, pois o novo ser que a ação coletiva, por intermédio da educação ética, constrói, representa neles o que há de melhor, de propriamente humano $(1995$, p. 36). Seria essa submissão uma nova forma de "servidão voluntária"? 0 homem como que anularia voluntariamente a si mesmo para ser o que a sociedade quer que ele seja? Estaria o coletivo, que submete, livre das tensões e desigualdades sociais que caracterizam os homens e as sociedades humanas em suas lutas históricas pela sobrevivência? E Durkheim enfatiza ainda que, mesmo quando as qualidades parecem à primeira vista espontaneamente desejadas pelos indivíduos, refletem já as exigências do meio social, que as prescreve como necessárias (1995, p. 36). Ou seja, não só a vida pessoal e moral estariam como que submetidas aos desígnios da sociedade, mas até o desejo, as pulsões, admite o sociólogo, estariam administrados.

E Theodor Adorno, músico e filósofo que viveu em Frankfurt, Alemanha, de 1903 a 1969, como responderia à questão levantada por Marilena Chauí? Em seu texto “Educação - para quê?", resultante da conversa com Becker, na Rádio de Hessen, em setembro de 1966, resgata o conceito kantiano de autonomia (maioridade) e o de Durkheim de adaptação (submissão), sem deixar de criticar-lhes as referências. Instigado por Becker de que é preciso tomar cuidado para não converter a ideia de "autonomia" em um ideal orientador, em algo demasiado abstrato, Adorno insiste em que é preciso inserir esse conceito no pensamento e também na prática educacional. A própria organização do mundo em que se vive e a ideologia dominante exercem uma pressão tão intensa sobre as pessoas, que supera toda a educação. Tem-se, pois, que, na busca da autonomia, levar em conta o peso incomensurável do obscurecimento 
da consciência impingido pelo próprio contexto em que o sujeito vive. Se, de um lado, autonomia significa o mesmo que conscientização de uma realidade determinada, essa comprovação da realidade envolve continuamente um movimento de adaptação. E a tensão entre essas duas dimensões constitutivas da educação é assim caracterizada:

A educação seria impotente e ideológica se ignorasse o objetivo de adaptação e não preparasse os homens para se orientarem no mundo. Porém ela seria igualmente questionável se ficasse nisto, produzindo nada além de well adjusted people, pessoas bem ajustadas, em consequência do que a situação existente se impõe precisamente no que tem de pior. Nestes termos, desde o início existe no conceito de educação para a consciência e para a racionalidade uma ambiguidade. Talvez não seja possível superá-la no existente, mas certamente não podemos nos desviar dela. (Adorno, 2003, p. 143-144).

Na continuidade da conversa radiofônica com Becker, Adorno insiste em que a educação/formação não é abstrata; ela é histórica e sua importância em relação à realidade muda progressivamente. Ainda mais, como já tinha assinalado, a realidade em seus dias se tornou tão poderosa ao impor-se sobre o indivíduo, desde a infância, que o processo de adaptação se realiza então de um modo como que automático. Se assim é, avança Adorno, o processo educacional, tanto na família quanto na escola e na universidade, teria neste momento de "conformismo onipresente" a tarefa de fortalecer muito mais a resistência que a adaptação. Por ser esse processo tão desmedidamente forçado por todo o contexto em que os homens vivem, "eles precisam impor a adaptação a si mesmos de um modo dolorido". E uma das tarefas educacionais mais decisivas a ser implementada, e já na primeira infância, é a crítica desse realismo social supervalorizado (Adorno, 2003, p. 144-145).

Há na referência acima uma acentuada controvérsia entre Durkheim e Adorno; o sociólogo enfatiza que "mesmo quando as qualidades parecem à primeira vista espontaneamente desejadas pelos indivíduos, refletem já as exigências do meio social que as prescreve como necessárias"; e o pensador frankfurtiano responde que os homens, para sobreviverem no social, "precisam impor a adaptação a si mesmos de um modo dolorido". No primeiro caso, até na aparente postura livre e ativa do indivíduo se manifesta a ação impositiva da sociedade; no segundo caso, há uma participação ativa e impositiva do indivíduo sobre si mesmo em sua submissão à sociedade.

Portanto Adorno responderia a Chauí que a educação moral é sim uma forma de violência que se manifesta historicamente na imposição ao indivíduo das leis morais, por meio da educação, com o objetivo de subjugar os seus impulsos e fazer dele um ser social; e que essa submissão se faz de maneira sofrida, com a colaboração do próprio indivíduo, que, para sobreviver, enquanto ser humano, precisa adaptar-se à 
sociedade em que vive; porém, acrescenta Adorno, é nessa tensão entre seus desejos e as imposições do social, entre a necessidade de integração e a resistência, que o indivíduo se vai formando crítica e moralmente.

Mas é no livro Minima Moralia, escrito no exílio, nos anos 1942-45, que Adorno, utilizando de pequenos aforismos e de forma estético-filosófica, desnuda muitas máscaras usadas pela falsa consciência na abordagem da tensa relação individuo e sociedade. É nessa direção que o texto avança, agora, sempre instigado pelo questionamento de Chauí. Destacaremos a seguir apenas alguns fragmentos críticos do livro.

A perversa lógica da adaptação. No aforismo $A$ saúde para a morte, Adorno considera que, se fosse possível uma psicanálise da cultura, tal investigação mostraria que a enfermidade própria da época seria precisamente o julgar tudo normal; que os desempenhos sociais que são exigidos de um indivíduo em sua conduta "politicamente correta" são de tal ordem que só podem ser realizados à custa das mais profundas mutilações pessoais; que ainda não se explorou a fundo o inferno em que se forjam tais deformações, que, posteriormente, surgem sob a forma de uma sociabilidade administrada, de uma adaptação bem-sucedida ao inevitável, como um senso prático bem resolvido. Há razões para supor, sublinha o frankfurtiano, que o processo de adaptação se inicia antes mesmo da origem das neuroses, como uma espécie de intervenção pré-histórica que inibe as forças antes mesmo de surgir qualquer conflito. Ou seja, há um triunfo da instância coletiva antes mesmo de a criança começar a se afirmar como indivíduo. As manifestações de normalidade na luta insana por um trabalho mais bem-remunerado, no ter que engolir grosserias e assédios das chefias para manter a posição no emprego ou no grupo social, são resultantes do que foi sufocado, das tensões terríveis há muito olvidadas, de vestígios da vida que já se foi. Adorno enxerga ainda outro aspecto do funesto "ser tudo normal": que o sacrifício que se exige do indivíduo é tão universal, que ele se patenteia nas manifestações do todo, e não do particular; ou seja, é como se a sociedade assumisse a doença do indivíduo e, em todas as suas mediações e intervenções, o mal subjetivo profundamente encravado no indivíduo se integrasse à desgraça objetiva inteiramente visível no social. 0 pensamento central desse aforismo assim se expressa: "Na base da sociedade reinante está a morte" (Adorno, 1992, p. 49-51; 2008, p. 54-56)2.

A adaptação não é um ato puramente individual. De um lado, analisa Adorno, pelo fato de o desenvolvimento tecnológico ter atingido um patamar elevado que permite hipoteticamente a todos desempenharem quase todas as funções na sociedade, surge a ilusão de que pertencer à elite seja algo possível a qualquer um: só se espera

2. Utilizamos as duas traduções do livro Minima Moralia, a de Luiz Eduardo Bicca, de 1992, e a de Gabriel Cohn, de 2008, pela complementaridade existente entre ambas na expressão do pensamento de Adorno. 
a cooptação e será privilegiado quem melhor se ajustar. Na verdade, os escolhidos continuarão sendo uma pequena minoria, mas a possibilidade de subir na vida é, muitas vezes, suficiente para manter a aparência de igualdade de oportunidades em um sistema que já eliminou a livre concorrência que se sustentava daquela aparência. 0 que decide do pertencimento a uma classe ou de sua queda não é a competência ou a incompetência, mas a própria estrutura hierárquica obtusa da sociedade, na qual ninguém se sente seguro, nem mesmo os que se encontram no topo: "é a democracia da ameaça", arremata Adorno (1992, p.170; 2008, p. 190). De outro lado, já vimos, o indivíduo não é apenas um frágil paciente tangido massivamente em seu enfrentamento do coletivo; há um esforço ingente e dorido seu para se integrar no todo; e esse esforço ingente de participar ativamente no social não é apanágio dos desfavorecidos; é a estúrdia sina de todos, até das pessoas do topo: elas, diz Adorno, "se esforçam tanto para se integrar, que todo desvio subjetivo torna-se impossível, e a diferença não pode ser buscada noutro lugar senão no modelo exclusivo de um vestido de noite" (Adorno, 1992, p.165; 2008, p. 184).

Todos têm que mostrar, o tempo todo, que se identificam com o poder do qual não cessam de receber pancadas; as pessoas devem amoldar-se àquilo que o sistema, triturando-as, força-as a ser. Todos podem ser como a sociedade, todo-poderosa, desde que se entreguem a ela de corpo e alma e renunciem a si mesmos. Diz o frankfurtiano em seu texto sobre "Indústria Cultural":

A idéia de que o mundo quer ser enganado tornou-se mais verdadeira do que, sem dúvida, jamais pretendeu ser. Não somente os homens caem no logro, como se diz, desde que isso lhes dê uma satisfação, por mais fugaz que seja, como também desejam essa impostura que eles próprios entrevêem; esforçam-se por fecharem os olhos e aprovam, numa espécie de autodesprezo, aquilo que thes ocorre e do qual sabem por que é fabricado. Sem o confessar, pressentem que suas vidas se thes tornam intoleráveis tão logo não mais se agarrem a satisfações que, na realidade, não o são. (Adorno, 1967, p. 96).

A Indústria cultural a serviço da adaptação. No aforismo Serviço ao cliente, questiona Adorno o tipo de atendimento prestado por esse agente ímpar de integração dos indivíduos na sociedade de consumo. A indústria cultural, de maneira interessada, proclama orientar-se pelos desejos dos clientes e oferecer-lhes aquilo que eles querem, como se estes fossem os seus guias e juízes; finge ser ela que se adapta às reações dos consumidores, que autonomamente escolhem o que é melhor para si; na verdade, é ela que inculca esse ajustamento aos clientes, comportando-se como se fosse um deles. As pessoas muito se empenham em igualar-se uns aos outros e ao 
todo no consumo e na semelhança, como se através dessa pseudoigualdade estivessem realmente participando da vida e do poder da sociedade. "A indústria cultural modelase pela regressão mimética, pela manipulação de impulsos de imitação recalcados". Para realizar isso, ela se serve do método de antecipar a imitação dela mesma pelo espectador e de apresentar como já existente o assentimento que ela pretende obter. Adorno, no aforismo, utiliza-se de duas analogias expressivas sobre a pressão da indústria da cultura no estímulo ao consumo e, sobretudo, na produção de um modelo de como reagir a estímulos inexistentes: a primeira ao insinuar que a máquina cultural avança sobre o consumidor como o trem expresso fotografado de frente no momento de maior suspense; a segunda ao comparar o apelo ao consumo à generosidade da velha bruxa que traz a refeição para a criança que ela pretende enfeitiçar ou devorar, sussurrando-lhe no ouvido: "Sopinha boa, não é gostosa a sopinha? Ela vai te fazer bem, vai fazer bem" (1992, p. 176; 2008, p.196-197). No aforismo 0 lobo como vovozinha, ele volta ao tema da indústria cultural, perguntando se o gosto das massas ao qual o cinema se diz dobrar não é das massas, e sim a elas imposto? E prossegue: De acordo com a lógica do sistema, “(...) é apenas na adaptação competente da produção às necessidades dadas, e não na consideração de uma autêntica audiência utópica, que é possível à anônima vontade universal ganhar forma" (1992, p. 179; 2008, p. 200). A incapacidade de distinguir entre necessidades autênticas e falsas se tornou difícil e sutil no capitalismo, em que o consumo e a indústria cultural nos impingem um volume expressivo de mercadorias como "necessárias" para nos tornarmos indivíduos de nosso tempo. Já dizia Adorno, no ano 1942, ao escrever Minima Moralia:

A ideia de que o cinema seja necessário, ao lado da habitação e da alimentação, para a reprodução da força de trabalho é "verdadeira" apenas em um mundo que prepara os homens para a reprodução da força de trabalho, violentando as necessidades humanas de acordo com o interesse da oferta e do controle social. (Adorno, 2004, p.367; 1998, p. 106).

O celular, o notebook, a internet, o I-pad se transformaram em "necessidades" mediadas pelo mercado deste mundo globalizado para manter seus usuários constantemente conectados no ritmo insano do sistema e não terem tempo para pensar, questionar, resistir. Há uma relação íntima entre as falsas necessidades e a adaptação ao sistema que oprime. Na verdade, elas, as “necessidades", são geradas e fabricadas em função da adaptação integral no todo e em contraposição à busca da autonomia do indivíduo. O homem contemporâneo se tornou antes de tudo um ser de consumo; se ele não consome, é inútil para a sociedade.

Resistir é permanecer no individual. Essa afirmativa, presente em diversas citações de Adorno em seus textos educacionais e éticos, não pode ser tomada numa dimensão 
psicologista. Na verdade, o pensador frankfurtiano está analisando o conceito de educação/formação ética e, na tensão entre a sociedade e o indivíduo, em tempos de um "conformismo onipresente", de um predomínio acentuado e assustador do todo sobre o particular, é preciso fortalecer antes a resistência que a adaptação, antes o indivíduo que a sociedade. 0 retorno ao sujeito, a acentuação do indivíduo como polo de resistência, não significa seu fechamento em si mesmo, mas sim a ênfase na busca de sua autonomia e de sua intervenção como alguém que pensa e que se expressa sem a tutela de outrem. Ainda mais, em tempos de enfraquecimento visível das forças sociais de oposição, a importância de se resgatar o potencial de resistência do indivíduo é um dos passos necessários para não se deixar tragar de vez pelo coletivo. Adorno, quando escreveu as Minima Moralia, já vimos, estava no exílio, nos Estados Unidos, como judeu, como pensador de esquerda, como estrangeiro, e essa condição de refém e de um indivíduo socialmente debilitado se reflete pesadamente em seus aforismos éticos, em sua proposta de acentuar a busca da autonomia e da resistência. E logo nas primeiras páginas, na Dedicatória do livro, o filósofo salienta essa perspectiva:

Em face da concórdia totalitária que apregoa imediatamente como sentido a eliminação da diferença, é possível que, temporariamente, até mesmo algo da força social de libertação tenha-se retirado para a esfera individual. Nela a teoria crítica se detém, não apenas com má consciência. (Adorno, 1992, p. 10; 2008, p. 12).

Em seu ensaio "Educação após Auschwitz”, escrito alguns anos após a dolorosa experiência nazista, constatando as extremamente reduzidas possibilidades de alterar os pressupostos objetivos (econômicos, sociais e políticos) da realidade em que vivia, Adorno ousa afirmar que as tentativas de combate à reincidência da barbárie - possível, pois as condições sociais objetivas que a geraram continuavam a existir - deveriam voltar-se para o lado subjetivo, que pode ajudar a conhecer os mecanismos que tornam os homens assim tão violentos e opressores. Diz ele: “Com a pressão do geral predominantemente sobre toda a particularidade, os indivíduos e as instituições individuais tendem a desintegrar o particular e o individual juntamente com sua capacidade de resistência" (Adorno, apud Cohn, 1986, p. 34-35).

No aforismo Para Anatole France, em que Adorno questiona a capacidade crítica do homem no julgamento do belo, em tempos em que o sujeito se capitula diante da supremacia alienada das coisas, novamente a ênfase no indivíduo é ressaltada: "Quem acha tudo belo arrisca-se a não achar nada belo. 0 universal da beleza só consegue se comunicar ao sujeito na obsessão do particular". Se a perspectiva do particular, da unilateralidade, é suprimida, afugentada ou substituída por uma consciência do universal introduzida de fora, então a possibilidade de se atingir o 
belo, como num "olhar sabático", também é ofuscada. "Seria quase possível dizer que a própria verdade depende do ritmo, da paciência e da perseverança do ato de permanecer no individual". 0 que vai além e avança para o julgamento sem ter-se primeiro detido longamente no particular, acaba se perdendo no vazio (Adorno, 1992, p. 66-67; 2008, p. 71-72). E termino este fragmento com mais uma citação das Minima Moralia, contida no aforismo Mônada:

Se hoje os últimos traços de humanidade parecem prender-se apenas ao indivíduo, como algo que se encontra em seu ocaso, eles nos exortam a por um fim àquela fatalidade que individualiza os homens tão-somente para poder quebrá-los por completo no seu isolamento. 0 princípio que preserva só se conserva ainda no seu contrário. (Adorno, 1992, p. 132; 2008, p. 147).

Como se vê, para Adorno, à medida que a sociedade avança em seu processo civilizatório, ela se torna mais impositiva sobre o indivíduo, procurando administrar seus desejos e sua vontade, ofuscando-lhe a sensibilidade, o conhecimento e a reflexão. 0 coletivo vai-se tornando mais impositivo, controlador e repressivo, e o indivíduo, para sobreviver - e, quem sabe, para tentar pequenas mudanças sociais -, tem que ser mais forte, resistente, crítico e solidário, ou seja, nadar contra a forte correnteza que o tempo todo o arrasta.

Mas Adorno desenvolvia suas reflexões sobre a educação e a ética há mais de cinquenta anos; suas análises, escritas em tempo da revolução mecânica, serão atuais em tempo das revoluções digital e genética, do capitalismo global? Pensamos que sim, pois o acelerado desenvolvimento tecnológico que caracteriza nosso momento e que, aparentemente, apresenta mais espaço de liberdade e de articulação ao indivíduo, na verdade fortalece mais e mais o social e os grupos que o dominam. Contudo, é essa uma questão pertinente que merece ser mais discutida no processo educacional e, particularmente, nas salas de aulas.

As contribuições de Kant, de Durkheim e, mais expressivamente, de Adorno na resposta às questões levantadas por Chauí nos ajudam a captar com mais densidade a tensão entre o individual e o social vivido pelos homens dos dias de hoje. Detivemonos mais demoradamente em Adorno, porque o frankfurtiano constrói o conceito de educação ética, no diálogo com Kant e Durkheim, enfatizando seus dois momentos contrapostos e, ao mesmo tempo, constitutivos: o da emancipação, destacado por Kant, e o da integração do indivíduo no social, defendido por Durkheim. E, mais ainda, porque Adorno, em seus fragmentos das Minima Moralia, coloca-nos em contato direto com os apelos e as exigências irrestritas que a sociedade tecnológica e de consumo impõe cada vez mais ao indivíduo, na contemporaneidade, sufocando sua 
busca de autonomia. E também porque, não obstante a constatação da triste realidade - e mesmo tendo-a como pressuposto -, é preciso, para os que ainda acreditam, continuar desenvolvendo o potencial transformador da educação/formação, que se coloca nos dias de hoje de maneira mais premente que nos dias de Kant, de Durkheim e de Adorno. Emancipar-se, falar com a própria boca, cultivar o inconformismo e a individualidade, desenvolver a arte de fazer experiência e de pensar, buscar a solidariedade, são mais do que nunca objetivos fundamentais de uma educação que quer ser crítica, formativa e contribuir para que o indivíduo avance nesse difícil e angustiante processo histórico de se tornar realmente individuum numa sociedade que o fragmenta e o pluraliza continuamente.

\section{Referências}

ADORNO, Theodor Wiesengrund. Minima Moralia: reflexões a partir da vida danificada. Tradução de Luiz Eduardo Bicca. São Paulo: Ática,1992.

. Educação após Auschwitz. In: COHN, Gabriel. Theodor W. Adorno. Tradução de Aldo Onesti. São Paulo: Ática, 1986, p. 33-45.

. Indústria Cultural. Tradução de Amélia Cohn. In: COHN, Gabriel. Theodor W. Adorno. Sociologia. São Paulo: Ática, 1986, p. 92-99.

Aldous Huxley e a utopia. In: ADORNO, Theodor Wiesengrund. Prismas: crítica cultural e sociedade. Tradução de Augustin Wernet e Jorge de Almeida. São Paulo: Ática, 1998, p. 91-116.

. Educação - para quê? In: ADORNO, Theodor Wiesengrund. Educação e Emancipação. Tradução e Introdução de Wolfgang Leo Maar. 3. ed., São Paulo: Paz e Terra, 2003.

- Tesis sobre La necessidad. In: ADORNO, Theodor Wiesengrund. Escritos sociológicos I. Obra Completa, 8. Madrid: Ediciones Akal, 2004, p. 365-368.

. Minima Moralia: reflexões a partir da vida lesada. Tradução de Gabriel Cohn. Rio de Janeiro: Beco do Azougue, 2008.CHAUÍ, Marilena. Convite à Filosofia. 13. ed. São Paulo: Ática, 2006. DURKHEIM, Emile. Educação e sociologia. Tradução de Lourenço Filho. 4. ed. São Paulo: Edições Melhoramentos, 1955.

KANT, Immanuel. Resposta à pergunta: que é o esclarecimento? In: KANT, Immanuel. Textos Seletos (edição bilíngue). Petrópolis: Vozes, 1985.

. Crítica da Razão Prática. Tradução de Artur Morão. Lisboa: Edições 70, 1994.

. Sobre a Pedagogia. Tradução de Francisco Cock Fontanella. Piracicaba: Editora UNIMEP, 1996.

PASCAL, Georges. O Pensamento de Kant. Tradução de Raimundo Vier. 3. ed., Petrópolis: Vozes, 1990. 
Recebida 1a versão em fevereiro de 2012

Aprovada 2a versão em maio de 2012

Bruno Pucci, professor titular aposentado da UFSCar e professor titular da UNIMEP. Coordenador do Grupo de Pesquisa "Teoria Crítica e Educação" e bolsista de produtividade do CNPq. Publicou vários artigos, livros e capítulos de livros, com destaque para: Adorno: o poder educativo do pensamento crítico lem parceria com Antônio Zuin e Newton Ramos-de-Oliveira, VOZES, 2000); Teoria Crítica e Inconformismo: novas perspectivas de pesquisa (Organizador, Autores Associados, 2010). Suas temáticas atuais de Pesquisa: Teoria Crítica e Educação; Novas Tecnologias e Educação - EAD; Estética e Educação. E-mail: bpuccidunimep.br. 